\title{
Effect of Muthu Marunthu (a Herbal Formulation) on the Altered Antioxidant Status in Experimental Fibrosarcoma in Rats
}

\author{
Venugopal Palani, ${ }^{1}$ Kesavan Senthilkumaran, ${ }^{2}$ Sorimuthu Subramanian, ${ }^{2}$ \\ and Saminathan GovindASAMY ${ }^{2, *}$ \\ ${ }^{1}$ Department of Biochemistry, Islamiah College, \\ Vaniyambadi 635 752, India \\ ${ }^{2}$ Department of Biochemistry and Molecular Biology, \\ University of Madras, Guindy Campus, \\ Chennai 600 025, India \\ (Received April 23, 1998)
}

\begin{abstract}
Summary Muthu Marunthu, a herbal formulation, was used to study its anticancer effect on 3-methylcholanthrene-induced fibrosarcoma in rats. The effects of Muthu Marunthu on the tumor weight, on the activities of glutathione peroxidase (GSH-Px), superoxide dismutase (SOD), and catalase (CAT), and on the levels of lipid peroxide and glutathione (GSH) of liver and kidney were studied in the fibrosarcomabearing rats. The tumor weight was found to be reduced by the Muthu Marunthu treatment. In liver and kidney, the level of GSH and the activities of antioxidant enzymes such as GSH-Px, SOD, and CAT were decreased significantly, whereas the lipid peroxide content was increased significantly in fibrosarcoma rats. After Muthu Marunthu treatment, the GSH content and the activities of antioxidant enzymes were increased significantly with a concomitant decrease in the level of lipid peroxide. These observations clearly suggest that Muthu Marunthu can effectively normalize the fibrosarcoma-induced alterations to the antioxidant defense systems.
\end{abstract}

Key Words: fibrosarcoma, Muthu Marunthu (a herbal formulation), anticancer effect, antioxidant systems

Ayurveda, a system based on medicinal plants, is one of the medical systems of Indian origin that is gaining importance nowadays for its quality and unimaginable efficacy without any side effects. Many of the pharmacological principles of

* To whom correspondence should be addressed. 
the currently used anticancer agents have been initially isolated from plants. Many plant products have been identified to have anticancer agents active both against animal and human tumors [1]. The vinca alkaloids, vincristine and vinblastine, are obtained from the common periwinkle plant (Captharenthus roseus). Vincristine has a curative effect on pediatric and adult acute lymphocytic leukemia [2], and vinblastine was reported to have antitumor effects in germ cells of the testis and in advanced Hodgkin's disease [3]. Plumbagin isolated from the plants Plumbago zeylanica, Plumbago rosea, and Plumbago europea, all belonging to the family of Plumbaginaceae, was found to have anticancer activities against fibrosarcoma, $\mathrm{P}_{388}$ lymphocytic leukemia, and hepatoma [4]. Arbortristoside-A isolated from Nyctanthes arbortristis L. inhibited $80 \%$ of the growth of methylcholanthrene-induced fibrosarcoma in albino rats at the dose of $2.5 \mathrm{mg} / \mathrm{kg}$ body weight, when given intratumorally [5]. Echitamine chloride, an indole alkaloid from the bark of Alstonia scholaris, was reported to have an anticancer effect in fibrosarcoma rats $[6,7]$.

Most of the herbal drugs are a mixture of a number of plant ingredients. Their cumulative effect increases the efficacy of the drug in curing the diseases. Muthu Marunthu is a herbal formulation comprising 8 various plant ingredients and has been claimed to have an anticancer effect. Hence, in this present study, the effect of Muthu Marunthu on the altered antioxidant systems in 3-methylcholanthreneinduced fibrosarcoma rats was investigated.

\section{MATERIALS AND METHODS}

The present study was conducted with a preparation of Muthu Marunthu. Table 1 shows the drug composition. The above-mentioned plant ingredients were cleaned, dried, and pulverized and then passed through an 80-mesh sieve. The powdered form of the drug was suspended in Tween- 80 and administered to the rats.

Male Wistar rats of $80-100 \mathrm{~g}$ were obtained from King Institute of Preventive

Table 1. Drug composition of Muthu Marunthu.

\begin{tabular}{lccc}
\hline Plant name & Family & Part used & Composition (mg) \\
\hline Hygrophila spinosa J. Arnd. & Acanthaceae & Whole plant & 200 \\
Myristica malabarica Lamk. & Myristicaceae & Leaves & 100 \\
Clerodendron phlomidis Linn. & Verbenaceae & Whole plant & 50 \\
Corallocarpus epigaeus Hk.f. & Cucurbitaceae & Whole plant & 50 \\
Piper cubeba Linn. & Piperaceae & Whole plant & 200 \\
Mollugo cerviana Ser. & Ficoidaceae & Whole plant & 200 \\
Quercus incana Roxb. & Cupaliferae & Seeds & 100 \\
Mesua ferrea Linn. & Guttiferae & Flowers & 100 \\
\hline All plants were identified and authenticated by Dr. T.R. Radhakrishnan, Professor and \\
Honorary Project Officer, Drug Standardisation Research Unit, Post-Graduate Department \\
of Chemistry, The New College, Chennai.
\end{tabular}


Medicine, Chennai, India. They were kept in well-ventilated polypropylene cages in a room with $12 \mathrm{~h}$ of light and $12 \mathrm{~h}$ of darkness. The animals were fed Hindustan Lever diet, and water was provided ad libitum. Fibrosarcoma was induced in rats in accordance with the procedure of Nagarajan and Sankaran [8]. Methylcholanthrene-induced fibrosarcoma was maintained in Wistar rats by serial implantation. About $0.2 \mathrm{ml}$ of $10 \%$ suspension in physiological saline of minced tumor cell lines were injected into the auxiliary region through a puncture in the inguinal region. The transplanted tumor took about a week to become palpable.

The rats were divided into four groups, namely, normal, Muthu Marunthutreated control, fibrosarcoma, and Muthu Marunthu-treated fibrosarcoma rats. Muthu Marunthu dissolved in Tween- 80 was injected daily for 20 days $(5 \mathrm{mg} / \mathrm{kg}$ body weight) subcutaneously starting 10 days after tumor implantation to the fourth group of rats, whereas the third group of rats received Tween- 80 only. The second group of control rats received Muthu Marunthu ( $5 \mathrm{mg} / \mathrm{kg}$ body weight) in Tween- 80 for 20 days. The day on which the tumor was implanted into the rat was taken as the zero day. The animals were sacrificed by cervical decapitation at the end of the 30th day, and blood was collected with ethylenediaminetetraacetic acid (EDTA) used as an anticoagulant. The liver and kidney were dissected out, and a known weight of liver and kidney tissue were homogenized in $0.1 \mathrm{M}$ Tris- $\mathrm{HCl}$ buffer $(\mathrm{pH} 7.4)$ at $4^{\circ} \mathrm{C}$ in a Potter Elvehjem homogenizer with a Teflon-pestle rotated at $600 \mathrm{rpm}$ for $3 \mathrm{~min}$.

Tumor weight was taken at 10-day intervals during the experimental period according to the method of Geren et al. [9]. The homogenate was used for the assay of glutathione peroxidase (GSH-Px; EC 1.11.1.19) [10], superoxide dismutase (SOD; EC 1.15.1.1) [11], catalase (CAT; EC 1.11.1.6) [12], glutathione (GSH) [13], and lipid peroxides [14]. The data were statistically analyzed, and Student's $t$-test was used to compare the means of two groups.

\section{RESULTS}

Figure 1 shows the tumor weight in fibrosarcoma and Muthu Marunthutreated fibrosarcoma rats. During Muthu Marunthu treatment, the tumor weight was found to be reduced significantly when compared to the tumor weight in untreated fibrosarcoma rats.

Table 2 depicts the activities of GSH-Px, SOD, and CAT in the liver and kidney of all four groups of rats. A significant decrease in the activities of GSH-Px, SOD, and CAT was observed in the liver and kidney of fibrosarcoma rats. These altered enzyme activities were brought back to near normal after treatment with Muthu Marunthu. Muthu Marunthu treatment did not have any significant effect on these enzymes in the control rats.

GSH content and lipid peroxide levels in the liver and kidney of normal, Muthu Marunthu-treated control, fibrosarcoma, and Muthu Marunthu-treated fibrosarcoma rats are presented in Table 3. The GSH content was decreased 


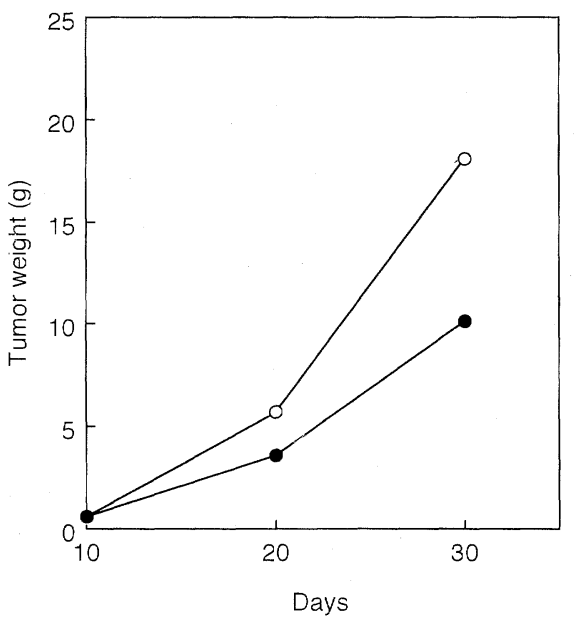

Fig. 1. Tumor weight in fibrosarcoma and Muthu Marunthu-treated fibrosarcoma rats. $\bigcirc-\bigcirc$ Untreated tumor; $\bullet-$ treated tumor.

Table 2. Activities of GSH-Px (nmol GSH oxidized $/ \mathrm{min} / \mathrm{mg}$ protein), SOD (50\% inhibition of adrenaline autoxidation) and CAT ( $\mathrm{nmol}$ of $\mathrm{H}_{2} \mathrm{O}_{2}$ decomposed $/ \mathrm{min} / \mathrm{mg}$ protein) in liver and kidney of normal, Muthu Marunthu-treated control, fibrosarcoma, and Muthu Marunthu-treated fibrosarcoma rats.

\begin{tabular}{llcccc}
\hline & Normal & $\begin{array}{c}\text { Muthu Marunthu- } \\
\text { treated control }\end{array}$ & $\begin{array}{c}\text { Fibrosarcoma } \\
\text { rats } \\
\text { (30th day) }\end{array}$ & $\begin{array}{c}\text { Muthu Marunthu- } \\
\text { treated fibrosarcoma rats } \\
\text { (30th day) }\end{array}$ \\
\hline GSH-Px & Liver & $99.28 \pm 5.5$ & $101.40 \pm 5.4$ & $76.4 \pm 3.6^{* 1}$ & $88.06 \pm 3.8^{* 3}$ \\
& Kidney & $50.23 \pm 4.4$ & $47.00 \pm 4.3$ & $35.23 \pm 2.6^{* 1}$ & $42.73 \pm 2.1^{* 3}$ \\
SOD & Liver & $8.37 \pm 0.75$ & $8.43 \pm 0.67$ & $5.84 \pm 0.48^{* 1}$ & $7.25 \pm 0.57^{* 3}$ \\
& Kidney & $4.22 \pm 0.21$ & $4.34 \pm 0.19$ & $2.75 \pm 0.12^{* 1}$ & $3.63 \pm 0.16^{* 3}$ \\
CAT & Liver & $71.54 \pm 5.6$ & $73.54 \pm 5.7$ & $58.21 \pm 4.2^{* 1}$ & $67.54 \pm 4.8^{* 2}$ \\
& Kidney & $8.10 \pm 0.55$ & $8.76 \pm 0.52$ & $4.80 \pm 0.39^{* 1}$ & $7.44 \pm 0.46^{* 3}$ \\
\hline
\end{tabular}

Values are expressed as the mean \pm SD for six animals in each group. ${ }^{* 1} p<0.001$, vs. normal; ${ }^{* 2} p<0.01,{ }^{* 3} p<0.001$, vs. fibrosarcoma rats.

significantly in the liver and kidney of the fibrosarcoma rats, whereas the lipid peroxide level showed a significant increase. The decrease in the GSH content and the increase in lipid peroxide level were largely prevented by the Muthu Marunthu treatment. No significant difference was noticed between the treated controls and the normals.

\section{DISCUSSION}

Tumor weight measurements are commonly used to study the anticancer nature of a given drug. It has been reported the plumbagin and echitamine 
Table 3. GSH (nmol/g wet tissue) content and lipid peroxide (LP) (nmol MDA/mg protein) level in liver and kidney of normal, Muthu Marunthu-treated control, fibrosarcoma, and Muthu Marunthu-treated fibrosarcoma rats.

\begin{tabular}{llcccc}
\hline & Normal & $\begin{array}{c}\text { Muthu Marunthu- } \\
\text { treated control }\end{array}$ & $\begin{array}{c}\text { Fibrosarcoma } \\
\text { rats } \\
\text { (30th day) }\end{array}$ & $\begin{array}{c}\text { Muthu Marunthu- } \\
\text { treated fibrosarcoma rats } \\
\text { (30th day) }\end{array}$ \\
\hline GSH & Liver & $6.84 \pm 0.48$ & $7.14 \pm 0.54$ & $3.96 \pm 0.23^{* 2}$ & $5.43 \pm 0.31^{* 4}$ \\
& Kidney & $3.65 \pm 0.31$ & $3.83 \pm 0.25$ & $3.26 \pm 0.27^{* 1}$ & $3.42 \pm 0.29$ \\
LP & Liver & $144.30 \pm 10.0$ & $140.14 \pm 9.8$ & $196.39 \pm 12.5^{* 2}$ & $175.55 \pm 11.0^{* 3}$ \\
& Kidney & $81.85 \pm 4.5$ & $79.77 \pm 4.3$ & $121.44 \pm 6.0^{* 2}$ & $100.60 \pm 5.6^{* 4}$ \\
\hline
\end{tabular}

Values are expressed as the mean $\pm \mathrm{SD}$ for six animals in each group. ${ }^{* 1} p<0.05,{ }^{* 2} p<0.001$, vs. normal; ${ }^{* 3} p<0.05,{ }^{* 4} p<0.001$, vs. fibrosarcoma rats.

chloride produced 75 and $65 \%$ tumor regression in a fibrosarcoma system at a dose of 10 and $20 \mathrm{mg}$, respectively [15]. Echitamine chloride, a plant alkaloid, was also reported in another study to inhibit tumor growth, and the tumor weight was found to be reduced significantly by the treatment [6]. In our study, the tumor weight was found to be 66 and 56\% of that of the fibrosarcoma group after 10 and 20 days, respectively, of Muthu Marunthu treatment. Hence, the observed reduction in the tumor weight in Muthu Marunthu-treated fibrosarcoma rats clearly showed the growth inhibitory effect of Muthu Marunthu on fibrosarcoma cells.

Several biological defense mechanisms exist for the prevention of membrane damage due to lipid peroxidation such as the non-enzymic antioxidant GSH and enzymic antioxidants such as GSH-Px, SOD, and CAT. The pentose phosphate pathway provides NADPH for the reduction of oxidized GSH to reduced GSH catalyzed by GSH reductase, a flavoprotein enzyme containing FAD. In turn, reduced $\mathrm{GSH}$ removes $\mathrm{H}_{2} \mathrm{O}_{2}$ in a reaction catalyzed by GSH-Px, an enzyme that contains the trace element selenium. This reaction is important, since accumulation of $\mathrm{H}_{2} \mathrm{O}_{2}$ results in adverse effect on biological membranes.

A decreased level of GSH-Px in human hepatoma was reported by Casaril et al. [16]. Also, Bartkowiak and Bartkowiak [17] showed that the activity of CAT was distinctly lower in hepatoma-bearing rats than in normal rats. It has been reported that the activities of the detoxifying enzymes GSH-Px, SOD, CAT, and glutathione-S-transferase (GST) and GSH contents were significantly depressed by a tumor promoter [18]. Several authors have reported the severe impairment of antioxidant defense systems during tumor growth $[19,20]$. Decreased levels of antioxidant enzymes were reported in breast cancer [21] and uterine cervical carcinoma patients [22]. In the experimental fibrosarcoma condition, decreased antioxidants GSH-Px, SOD, and CAT were reported $[6,23]$. In this present study, the decreased activities of GSH-Px, SOD, and CAT in the liver and kidney of fibrosarcoma rats were increased significantly by Muthu Marunthu treatment, indicating its antioxidant property.

GSH either alone or in conjunction with other proteins can protect cells Vol. 25, No. 1, 1998 
against lipid peroxidation [24]. Corrocher et al. [25] have reported that a diminished level of GSH leads to overproduction of free radicals and consequently neoplastic transformation. Aruna and Sivaramakrishnan [26] observed an increase in GSH levels in stomach, liver, and esophagus in mice by treatment with spices and leafy vegetables. After Muthu Marunthu treatment, the drug restored the decreased GSH content in Muthu Marunthu-treated fibrosarcoma rats.

It has been suggested that increased lipid peroxidation would cause degeneration of tissues and that lipid peroxides formed in the primary site would be transferred through the circulation to other tissues and provoke damage by propagating the process of lipid peroxidation [27]. It was reported that the lipid peroxide levels of hepatic tissue rose significantly as the tumor progressed in mice bearing Lewis lung carcinoma [20]. Malondialdehyde (MDA), the end product of lipid peroxidation, was reported to be higher in carcinomatous tissue than in non-diseased organs [28]. Kamarajan et al. [6] and Vasavi et al. [29] reported a significant rise in lipid peroxide levels with a concomitant decrease in the enzymatic and non-enzymatic antioxidants during the growth of experimental fibrosarcoma. Elevated lipid peroxide levels clearly reflect the overproduction of free radicals and/or the inability of the antioxidant defense system to perform adequately during tumor growth. After Muthu Marunthu treatment, the increased level of MDA was found to be decreased in fibrosarcoma rats. Hence, the observed decrease in the lipid peroxides in Muthu Marunthu treatment may be due to its influence on free radical formation or to its ability to scavenge the reactive oxygen species.

It may be noted from the above observations that there was a significant reduction in tumor growth and correction of the altered levels of lipid peroxides and GSH and antioxidant enzymes such as GSH-Px, SOD, and CAT in the experimental fibrosarcoma following Muthu Marunthu administration. Hence, we conclude that the alterations of antioxidant defense systems in rats with 3-methylcholanthrene-induced fibrosarcoma were normalized after Muthu Marunthu treatment, indicating a possible protective role of Muthu Marunthu. Further, the observations made on the Muthu Marunthu-treated control rats indicate the non-toxic nature of Muthu Marunthu.

The authors wish to thank Dr. T.R. Radhakrishnan, Professor and Honorary Project Officer, Drug Standardisation Research Unit, Post-Graduate Department of Chemistry, The New College, Chennai, for providing the drug Muthu Marunthu and Dr. B. Nagarajan, Cancer Institute, Chennai, for providing the fibrosarcoma cell lines.

\section{REFERENCES}

1. Hartwell, J.L. (1976): Types of anticancer agents isolated from plants. Cancer Treat. Rep., 60, 1031-1067.

2. Aur, R.J.A., Simone, J.V., Verzosa, M.S., Hustu, H.O., Barker, L.F., Pinkel, D.P., Rivera, G., Dahl, G.V., Wood, A., Stagner, S., and Mason, C. (1978): Childhood acute lymphocytic leukemia-study. Cancer, 42, 2123-2134. 
3. Ravinsky, E.K., and Donehower, R.C. (1991): The clinical pharmacology and use of antimicrotubule agents in cancer chemotherapeutics. Pharmacol. Ther., 52, 35-84.

4. Mohana, K., and Purushothaman, K.K. (1980): Plumbagin-A study of its anticancer, antibacterial and antifungal properties. Indian J. Exp. Biol., 18, 876-877.

5. Susan, T., Alam, M., and Purushothaman, K.K. (1986): Inhibitory activity of Arbortristoside A on fibrosarcoma in albino rats. Arogya J. Health Sci., 7, 122-130.

6. Kamarajan, P., Sekar, N., Mathuram, V., and Govindasamy, S. (1991): Antitumor effect of echitamine chloride on methylcholanthrene induced fibrosarcoma in rats. Biochem. Int., 25, 491-498.

7. Kamarajan, P., Sekar, N., and Govindasamy, S. (1995): Anticancer effect of echitamine chloride on plasma vitamins and minerals in rats with methylcholanthrene induced fibrosarcoma. Med. Sci. Res., 23, 237-239.

8. Nagarajan, B., and Sankaran, S. (1973): A rapid method for the production of fibrosarcoma. Indian J. Cancer, 10, 83-84.

9. Geren, R.I., Greenberg, N.H., Macdonald, M.M., and Schumacher, A.M. (1972): Protocols for screening chemical agents and natural products against animal tumors and other biological systems (3rd ed.). Cancer Chemotherapeutic Reports, Part 3 (2).

10. Necheles, T.F., Boles, T.A., and Allan, D.M. (1968): Erythrocyte glutathione peroxidase deficiency and hemolytic disease of the newborn infant. J. Pediatr., 72, 319-324.

11. Misra, H.P., and Fridevich, I. (1972): The role of superoxide anion in the autoxidation of epinephrine and a simple assay for superoxide dismutase. J. Biol. Chem., 247, 3170-3175.

12. Takahara, S., Hamilton, B.H., Nell, J.V., Kobara, J.Y., Ogura, Y., and Nishimura, E.T. (1960): Hypocatalasemia: A new genetic carrier state. J. Clin. Invest., 39, 610-619.

13. Moron, M.S., Depierre, J.W., and Mannervik, B. (1979): Levels of glutathione, glutathione reductase and glutathione-S-transferase activities in rat lung and liver. Biochim. Biophys. Acta, 582, 67-78.

14. Ohkawa, H., Ohishi, N., and Yagi, K. (1979): Assay for lipid peroxides in animal tissue by thiobarbituric acid reaction. Anal. Biochem., 95, 351-358.

15. Chandrasekaran, B., and Nagarajan, B. (1983): Growth inhibitory effect of echitamine and plumbagin on fibrosarcoma in rats. Arogya J. Health Sci., IX, 60-63.

16. Casaril, M., Gabrielli, G.B., Dusi, S., Nicoli, N., Bellisola, G., and Currocher, R. (1985): Decreased activity of liver glutathione peroxidase in human hepatocellular carcinoma. Eur. J. Cancer Clin. Oncol., 21, 941-944.

17. Bartkowiak, A., and Bartkowiak, J. (1981): Superoxide dismutase and catalase activities in normal and cancerous tissues. Comp. Biochem. Physiol., 70, 819-820.

18. Perchellet, E.M., Matta, E.A., Abney, N.L., and Perchellet, J.P. (1987): Effects of diverse intracellular thiol delivery agents on glutathione peroxidase activity, the ratio of reduced/ oxidized glutathione, and ornithine decarboxylase induction in isolated mouse epidermal cells treated with 12-o-tetradecanoylphorbol 13-acetate. J. Cell. Physiol., 131, 64-73.

19. Roy, D., and Liehr, J.G. (1989): Changes in activities of free radical detoxifying enzymes in kidneys of male syrian hamsters treated with estradiol. Cancer Res., 49, 1475-1480.

20. Capel, I.D., and Thornley, A.C. (1982): Superoxide dismutase activity, ceruloplasmin activity and lipoperoxide levels in tumor and host tissues of mice bearing the Lewis lung carcinoma. Eur. J. Cancer Clin. Oncol., 18, 507-513.

21. Kumar, K., Thangaraju, M., and Sachdanandam, P. (1991): Changes observed in antioxidant system in the blood of post-menopausal women with breast cancer. Biochem. Int., 25, 371-380.

22. Balasubramanian, N., Subramanian, S., and Govindasamy, S. (1994): Status of antioxidant systems in human carcinoma of uterine cervix. Cancer Lett., 87, 187-192.

23. Chitra, M., Sukumar, E., and Shyamala Devi, C.S. (1994): Protective action of embelin against lipid peroxidation in tumour bearing rats. Fitoterapia, 55, 317-321.

24. Tirmentsein, M.A., and Reed, D.J. (1988): Characterization of glutathione-dependent inhibition of lipid peroxidation of isolated rat liver nuclei. Arch. Biochem. Biophys., 261, 1-11.

Vol. 25, No. 1, 1998 
25. Corrocher, R., Casaril, M., Guidi, G.C., Gabrielli, G.B., Miatto, O., and De Sandre, G. (1980): Glutathione-peroxidase and glutathione-reductase activities of normal and pathologic human liver relationship with age. Scand. J. Gastroenterol., 15, 781-786.

26. Aruna, K., and Sivaramakrishnan, V.M. (1990): Plant products as protective agents against cancer. Indian J. Exp. Biol., 28, 1008-1011.

27. Maseki, M., Nishigaki, I., Hagihara, M., Tomoda, Y., and Yagi, K. (1981): Lipid peroxide levels and lipid content of serum lipoprotein fractions of pregnant subjects with or without pre-eclampsia. Clin. Chim. Acta, 115, 155-162.

28. Yagi, K. (1987): Lipid peroxides and human diseases. Chem. Phys. Lipids, 45, 337-351.

29. Vasavi, H., Thangaraju, M., and Sachdanandam, P. (1994): Effect of $\alpha$-tocoferol on lipid peroxidation and antioxidant system in fibrosarcoma bearing rats. Mol. Cell. Biochem., 131, $125-130$. 